\title{
II Macrothink \\ Current Development on Cloud Computing Service Models for End Users Data Analysis
}

\author{
Nur Hamezah Abdul Malic @ Abdul Malik \\ Faculty of Information Management \\ Universiti Teknologi MARA UiTM \\ UiTM Selangor, Malaysia \\ Tel: 603-6177-4407Ｅ-mail: hamezahmalic@gmail.com
}

\author{
Tengku Adil Tengku Izhar \\ Faculty of Information Management \\ Universiti Teknologi MARA UiTM \\ UiTM Selangor, Malaysia
}

Tel: 603-9762-2309 E-mail: tengkuadil@yahoo.co.uk

\author{
Mohd Razilan Abdul Kadir \\ Faculty of Information Management \\ Universiti Teknologi MARA UiTM \\ UiTM Selangor, Malaysia
}

Tel: 603-7962-2142Ｅ-mail: mrazilan@gmail.com

Received: February 9, 2019 Accepted: February 25, 2019 Published: June 3, 2019

doi:10.5296/ijld.v9i2.14884 URL: https://doi.org/10.5296/ijld.v9i2.14884 


\begin{abstract}
The emerging cloud computing has lead society to accept this technology advancement in their daily life. Referring to the past studies, it is found that there are few factors that effecting the usage satisfaction in using cloud computing services. Many cloud computing providers are always competing to give users the best feature out of their offered services. However, it should consider knowing the factors that contribute to the usage satisfaction. This paper reviewed the previous study on cloud computing services. We compare previous models on cloud computing to analyse current gaps on critical factors toward future framework development. The reviews contain relevant factors such as security, efficiency and performance, cost, organisation and technology developed based from the literature.
\end{abstract}

Keywords: adoption, cloud computing, service models, usage satisfaction

\title{
1. Introduction
}

Cloud computing is a powerful enabling tool for transforming in delivering and accessing educational as well as provisioning of online learning, research collaboration and most importantly in teaching (Temitayo \& Comfort, 2014). They also stated that the required skills for the global workplace of cloud computing should be considered by organisations. A continually adapt to the working world together with innovations of technology needed to educate students. Cloud computing offers major flexibilities on the connected global community that can benefit the experts and peers to work and learn in collaborative a environment.

Kumar \& Murthy (2013) also stated that there are lots of research and studies attracted to cloud computing concepts and area over the last few years. There are so much to discover and learn from this computer alternatives. One of the pillar of society development are mostly come from private and public sector of higher education. It is proved that the entire economy of the world contributed by the partnership between universities, government and industries and students and governments. However, not many universities are opted for the cloud computing services solution due to the cost and economical context. Depending on many customise factors it might be affecting the cost.

Cloud computing started 2006 which about 12 years ago together with the increasing influence of the internet in our daily life. Cloud computing is growing bigger every day. Many private and public sector seriously consider moving to cloud computing and adopted cloud company based solutions (Kumar, 2013). User can now be using the cloud computing rather than using the software programs in the computer. In the university environment, the challenges for university to provide tool in prepare and educate students (Christopher, Temitayo, \& Comfort, 2014). Global workplace will enforce student to have required skill. Cloud computing is a solution that can be used many times. Concept of using programs, platform and infrastructure of computing resources over the internet are part of cloud computing. The aim of this paper is to review current development on cloud computing services. We compare previous models on cloud computing to analyse current gaps on critical factors toward future framework development. 
The remainder of this paper is organized as follows. Section 2 discusses the literature review. Section 3 discusses the gaps from the previous theoretical framework. The final section contains some concluding remarks.

\section{Literature Review}

Kumar \& Murthy (2013), conducted a study that involves cloud computing use of cloud computing and a prototype suggestion. The aim of this study is to discuss the development of cloud computing in universities and also seeking for the suggestions on a cloud computing prototype for university campus. The finding of this research finds that there are needs of cost planning and structure before developing a cloud computing for university. The cost breakdown of the cloud computing services in a university are the cost of departmental staff, operational staff, outsourcing, infrastructure, application software cost, network infrastructure, storage infrastructure and server infrastructure. However, focusing to the study that will be conducting, thus researcher would like to state that universities that implemented cloud computing able to reduce their energy, power and space constrains. In the same time, it also decreased their demand on licensed software which reduced their expenditure cost.

Lu, Lan and Lee (2013) conducted a study that involves incorporates TAM (technology acceptance model) and the duo-theme DEMATEL (decision making trial and evaluation laboratory). The proposed evaluation framework tested during the post-implementation on a university, a phase after introducing the internal cloud services. The aim of this study is to find out the reasons on why users unwilling to use cloud services in a university. Most of the users stated that the usability and the functionality component played an important role for the cloud computing services. The finding of the study shows that the urgency of usage of internal cloud in university are more focussing on "user friendly" impression which falls under the perceived ease of use.

Yuvaraj (2015) conducted a study on the implementation of university libraries cloud computing prospects and problems. This study used the quantitative method which involves questionnaire distributions to the library professionals. The cloud computing is now developing into the information gateways. Advancement of technology may not change the cloud into a conventional technology. With the increased use of cloud computing, the evaluation of the cloud computing must be conducted in order to improve the service and meet the user needs. Moreover, the organisations' willingness to adopt cloud computing. The finding shows that organisations need to consider encouraging and spending some money on sending students and employees to professional training courses or workshops. Other encouragement may also include material reward. Knowledge related with cloud computing is vital in order to provide best support of the service. Thus, organisation also encourage staff to participate in any related events such as conference that targeted for transformation of cloud computing services.

A good cloud computing should also promote the role of trust in using the services. In Adjei (2015) study, he conducted quantitative research which involves interviews and discussions with focus group for data collection. Based on literature review, this explanatory paper is based on empirical evidence from interviews conducted in financial institutions in Ghana 
which to explain the role of trust in cloud computing. There are a lot of benefits using cloud computing, however in the event of data breaches relating with the security risks. This security risks dilemma making them hard to make decisions on to disclose sensitive information to third parties. Lack of privacy compliance management and information security of cloud computing services posited. Organisation from other countries has also raised these concerns attributes to the security and privacy laws. Practical implementation of cloud computing can contribute to organisation and decision makers trust which to understand the impact and significant of cloud computing on the organisation. The finding shows the cloud computing trust towards the security from a financial institution and it can be increased if providers honest about the product.

In addition, Dhar (2012) compared cloud computing with global outsourcing and transformation of IT services. Dhar (2012) aim of this study is examine the transformation of traditional IT services by comparing it with global IT outsourcing to cloud computing services. This articles' findings emphasis the performance of the promised best practice and benefits if an organisation outsourcing its IT operations. Upon agreement organisation and cloud computing vendor, best deliverable of performance standards and outputs. The performance assurance and quality guaranteed by vendor by achieving the better response time, adoption of a higher standard and using latest and high-end technology. It is also seen providing 24/7 around the clock service is one of the main challenge faced by cloud computing providers. Huge potential losses may lead by the lack of this support may cause breach of service level agreements (SLA) and severe damage to the services. Thus, these issues must be addressed and solve by reducing the risk. It can be reduced by developing security policies and acceptable compliance along with performance assurance and guarantee.

Low, Chen \& Wu (2011), performed study on the cloud computing adoption understanding. The study managed to collect data from high-tech industry in Taiwan which in total eleven hundred and one firms using questionnaire based-survey. Low, Chen \& Wu (2011) conducted this study in order to examine factors of firms belonging to the high-tech industry adoption of cloud computing. It is found that the adoption of cloud computing has bring significant effect on the characteristics of relative advantage, top management support, trading partner pressure and competitive pressure. This study's value helps organisation in implementing cloud computing and most importantly the contribution of research in cloud computing adoption towards application of new technology.

\subsection{Security}

Cloud computing usually collect and store various type of information of its user. It remains problematic and vendor played important role in gaining user's trust. The issue of security with the use of cloud computing has brought up so many time. Sometimes the main challenges of cloud computing adoption are due to lack of trust from senior or top management of an organisation. They can't afford to worry and lose its data to outsource vendor's hand. Private clouds solution should be considered since it allows business to take control of how their data stored (Kaisler, Money, \& Cohen, 2012). 


\subsection{Efficiency and Performance}

Efficiency and performance played an important role in cloud computing. This is because the cloud computing was to make sure that the user will get the benefit from the service provided (Rafael, 2006). This efficiency and performance criteria is are used to know how the user feel feels about the value and quality of information provided in the cloud computing. Cloud computing that able to provide high efficiency and great performance can increase the usage satisfaction.

\subsection{Cost}

Adopting a new technology will always incurred a huge amount of cost. Other challenge of implementing cloud computing is how the new technology able to improve the business process compared to revamping the existing systems (Kumar, 2013). Public university universities are looking into cloud computing solution for them to reduce associated costs. Putting together and consolidate database server to cloud computing will reduces the workload of IT staff so they can give better provision on another matter, reduce buying new software license, reduce power and better management costs (Kumar, 2013). As a result, based on the cost it includes around the cloud support and the best part is IT staff headache will go away since the vendor will maintain the storage, servers, software infrastructure and switching in the cloud computing. This also includes the space, power and racks.

\subsection{Organisation}

Organisations such as libraries and educational institutions has been eyeing cloud computing as it able to concentrate more on the benefits of learning outcome (Yuvaraj, 2015). Some of the organisation are underutilised their fund since they keep holding back to upgrade the IT system. Organisation that hindering to accept the transformation of cloud computing due to there still few issues raised even though the advantages had been presented many times (Yuvaraj, 2015). However, there are few factors of organisation implementation of cloud computing such as their willingness to adapt cloud computing technology. Top management plays big role in providing sufficient support. Support could be in the term of constant incentives and motivations also helped the organisation to continuous for innovation (Yuvaraj, 2015). Sufficient training and education related to the implementation of cloud computing is also important since staffs are needed to have their own skill and competency to support the newly adopted technology.

\subsection{Technology}

Technology is a very vast subject. There are a lot of researches taking place about technology which if going in detail, it will be the cloud computing. Cloud computing technology has grabbed expertise' attention by its own functionality. In business process, technology used in cloud computing provides better advantages and usefulness (Gangwar, Date, \& Ramaswamy, 2015). TAM model, a model that able to explain the user and also successfully predicting the adoption of technologies is widely used across multiple research study worldwide (Gangwar et al., 2015). Previous experience is the main contributor in determining the degree of innovation. 
Table 1. Review of Analysis

\begin{tabular}{|c|c|c|c|c|c|c|}
\hline Authors & Security & Efficiency & Performance & Cost & Technology & Organisation \\
\hline Kaisler et al. (2012) & l & & & & & \\
\hline Rafael (2006) & & / & l & & & \\
\hline Kumar (2013) & & & & l & & \\
\hline Yuvaraj (2015) & & & & & & / \\
\hline Gangwar et al. (2015) & & & & & l & \\
\hline
\end{tabular}

\section{Review on Theoretical Framework}

The first theoretical framework review for this study taken from the study title "Innovative public governance through cloud computing: Performance measurement challenges, information privacy and business models" by Tsohou et al., (2014) examined the challenges of cloud computing in public governance. This paper conducted qualitative study which involves focus group in two different countries. It is found that the challenges can be overcome by using the suggested solutions derived from the design platform from the government. The study uses satisfaction for the study which will be adopted in this study.

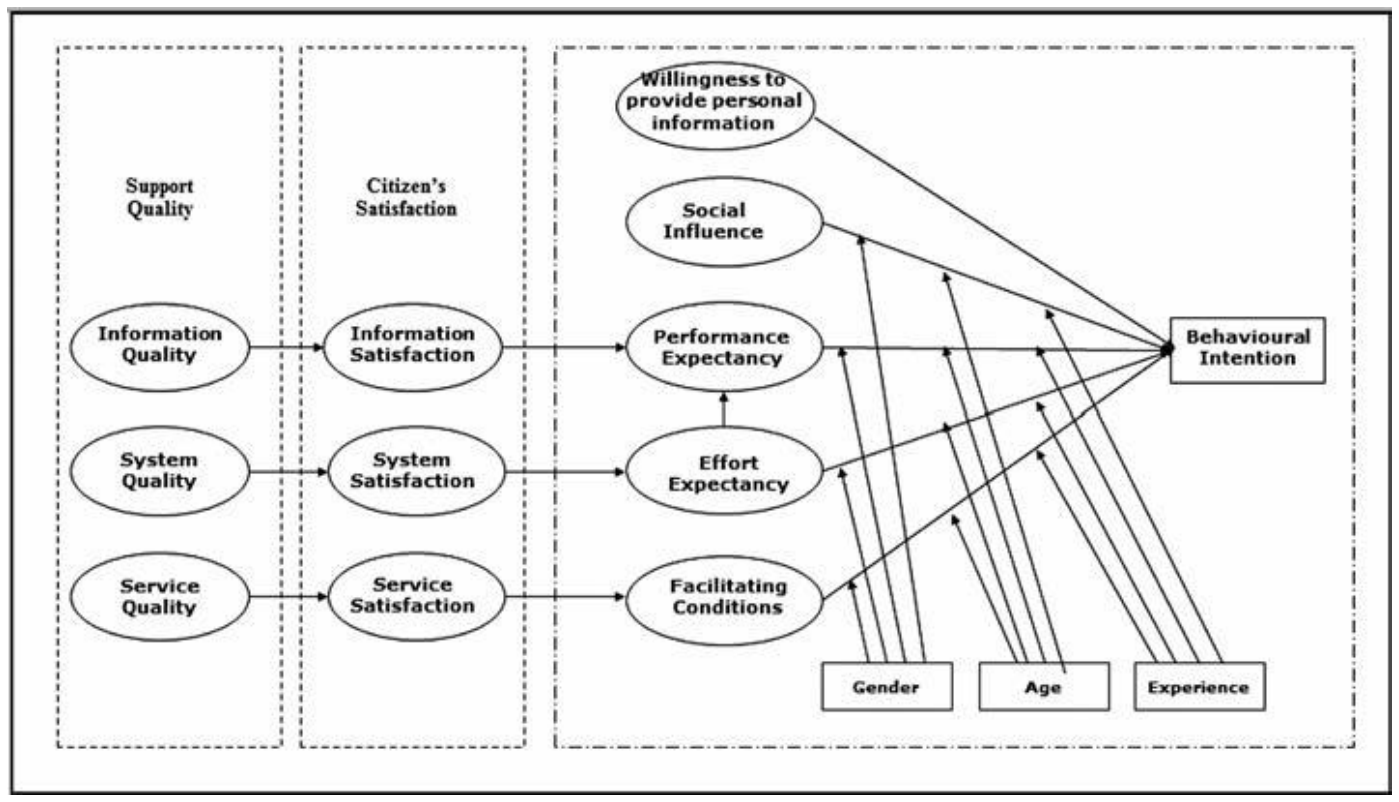

Figure 1. Integrated model for e-government services in the cloud (Aggeliki, Habin \& Irani, 2014)

Mohammed et al. (2016) addressed five public organisation in Yemen and focusing on twenty-six information technology staff among this organisation. The aim of this study is to study e-government services by developing a measurement to examine the factors influencing 


\section{Macrothink}

International Journal of Learning and Development

ISSN 2164-4063 2019, Vol. 9, No. 2

cloud computing adoption. In the research found there are eight instruments can be practically applied on the adoption of the cloud computing in e-government services. From the framework, the variable that will be used in this study is the technology (compatibility, relative advantage and complexity) and organisational factors (top management support). However for the variable organisational factors, training and education dimension is not available in the study performed by Mohammed, Ibrahim \& Ithnin (2016). The variables mentioned above are adopted in this study's framework since it will help this study to further evaluate the cloud computing services.

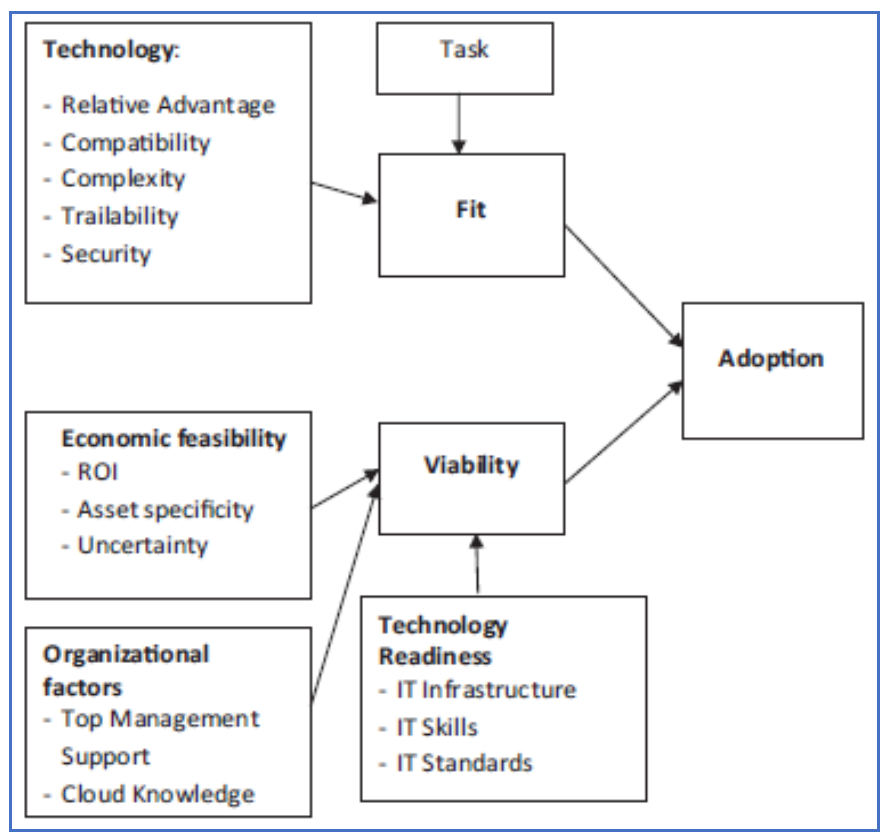

Figure 2. Models of Adopting Cloud Computing in the e-Government Context (Mohammed, Ibrahim \& Ithnin, 2016)

Gangwar et al., (2015) investigated the cloud computing adoption at organisation level by fitting in TOE framework and TAM model. Based on the reading, it is found that variable technology (relative advantage, compatibility and complexity) and organisation (training and education and top management support) will be adopted in this study. These IV will be adopting to help this study evaluate the cloud computing services in term of technology and organisational in order to meet the usage satisfaction. The figure below explained model adopted by authors. 


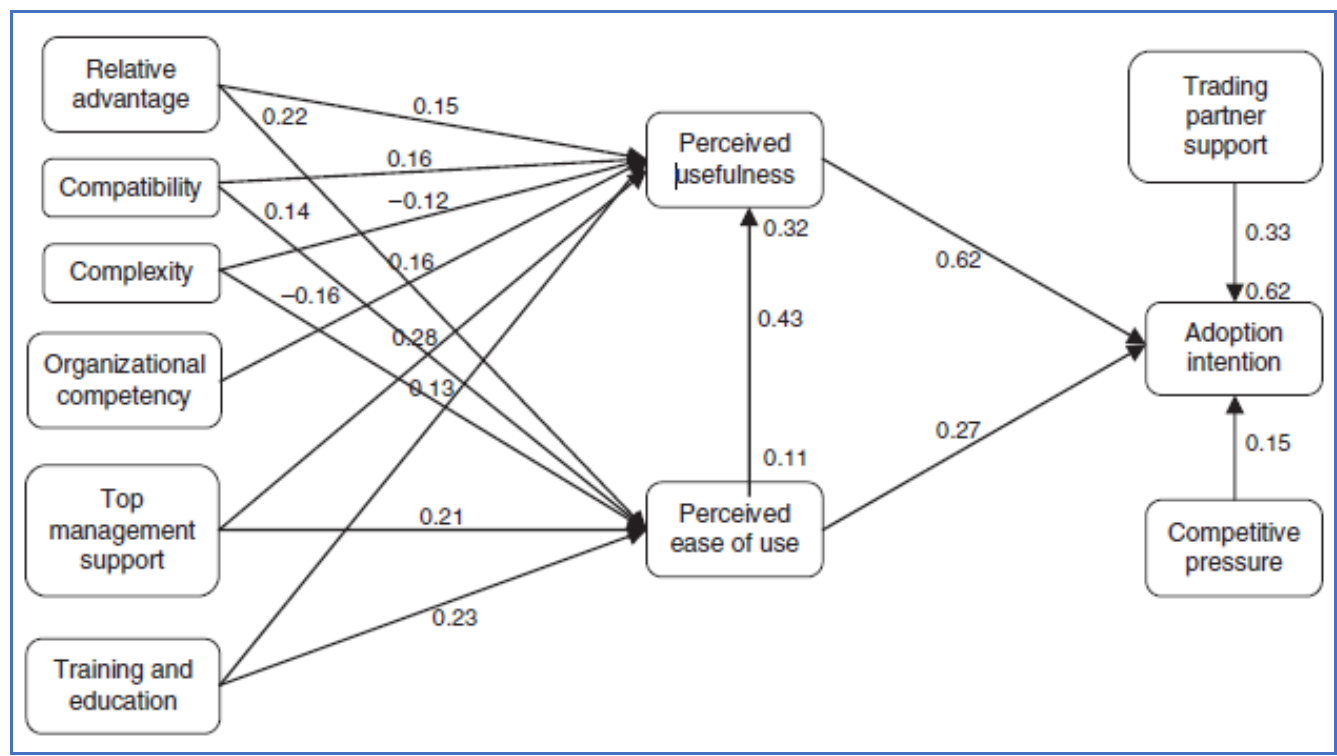

Figure 3. Adoption of TOE framework and TAM model used in the study (Gangwar, Date \& Ramaswamy, 2015)

In addition, Kaisler et al. (2012), they surveyed for about 80 research articles from journals, symposia, blogs, commercial announcements and claims, books and conferences. The aim of this research is to assist management that is determining to have cloud computing services as their solution while looking at the benefits derived from the cloud's value. The study developed a decision framework for adopting cloud computing. Upon further reading it found that security is listed as one of the variable used in the study. From the study, the security IV will be adopted in the upcoming research. This is because to evaluate the security of cloud computing services.

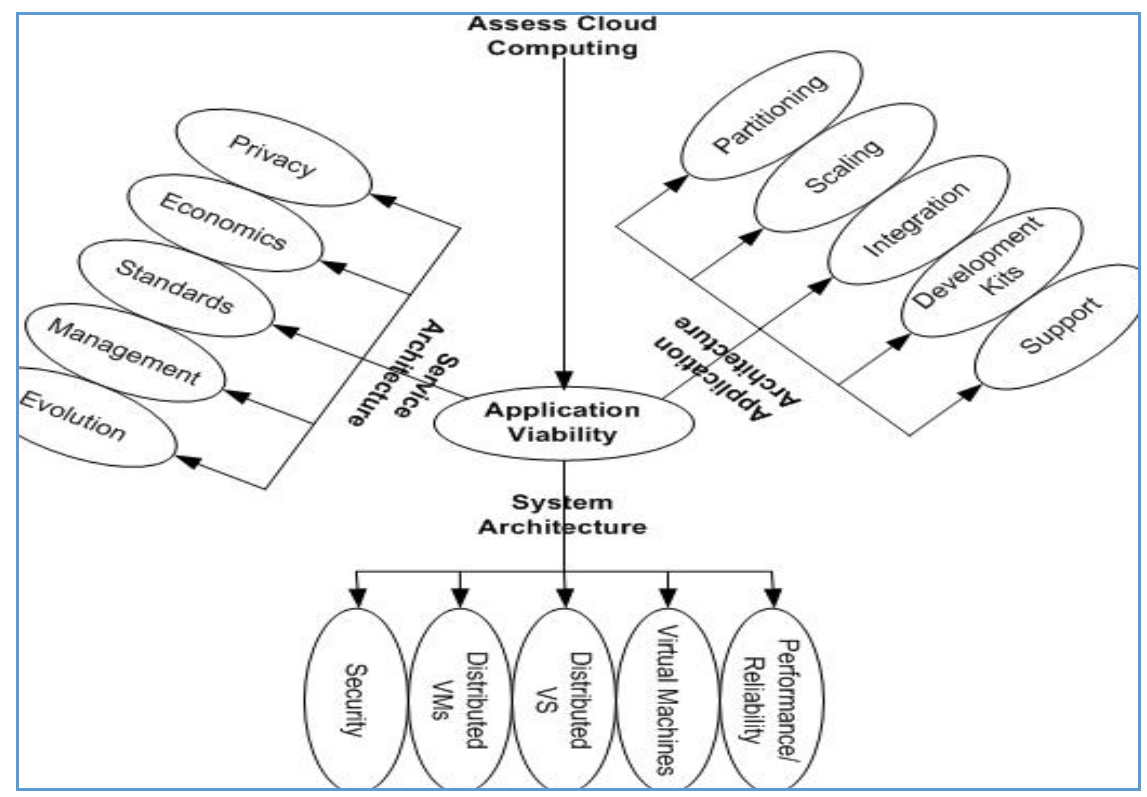

Figure 4. Decision Framework for Adopting Cloud Computing (Kaisler, Money, \& Cohen, 2012) 


\section{Macrothink}

International Journal of Learning and Development

ISSN 2164-4063 2019, Vol. 9, No. 2

Martens et al. (2015) explored the significant benefits for an organisation from using cloud computing services. The study conducted in mixed method approached from analysis of cloud computing services and also literature review. From the research, it found that cost (hardware \& software) is one of the important variable will be used to conduct this study. This is due to cost is one of the important factors to evaluate the usage satisfaction in using cloud computing services.

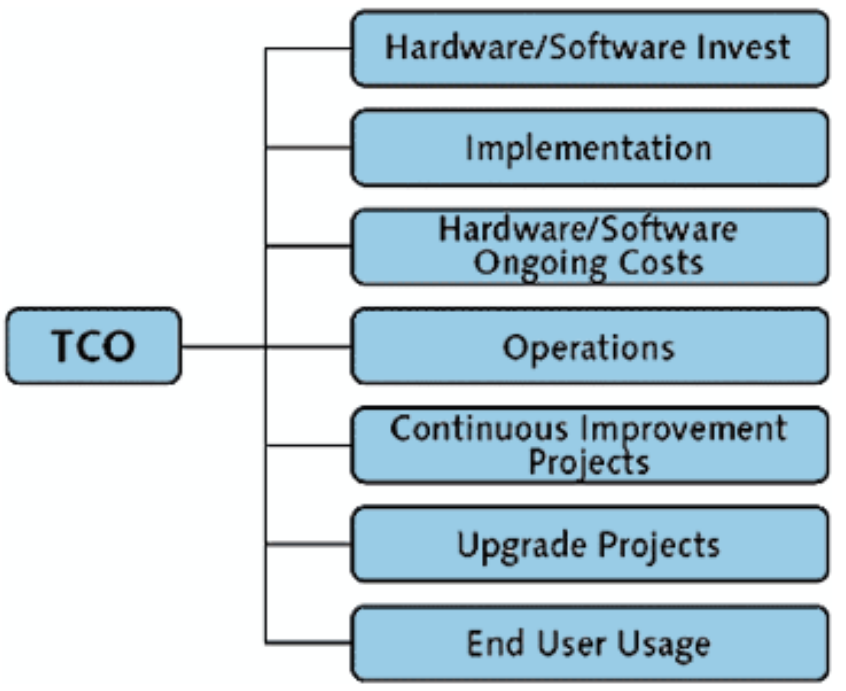

Figure 5. TCO Model used by authors in this study

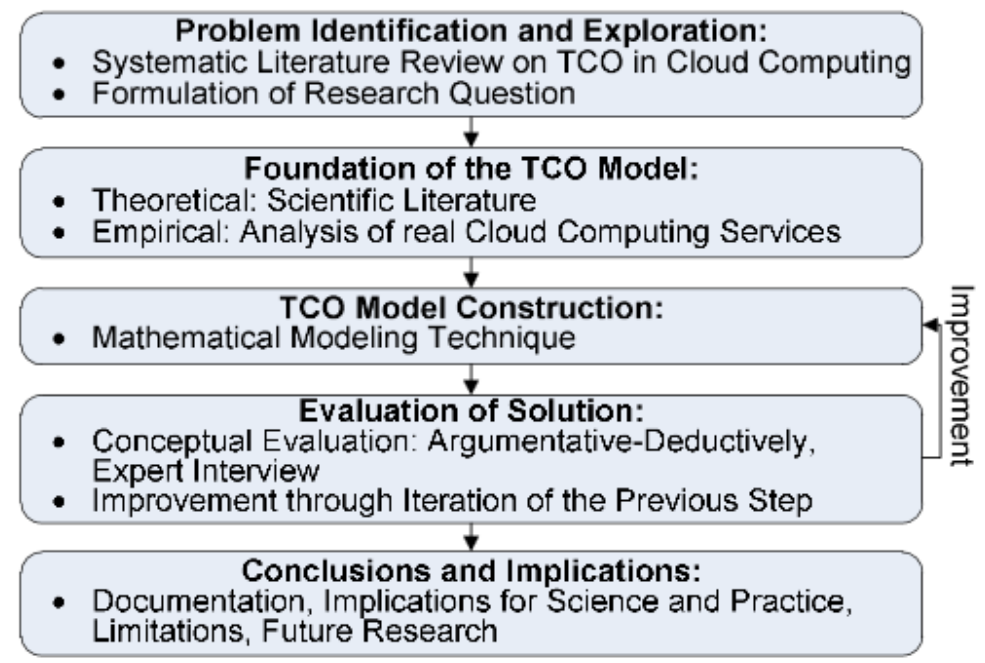

Figure 6. Aligning TCO Model with research approach

Deepak et al. (2016) studied on emerging context of new IT service delivery models, the purpose of this study is to connect gap of e-Government performance with IT infrastructure capability. This paper conducted case study which data collected from an interview. The dimension model as shown below, researcher will be adopting the variable of user satisfaction and performance. As performance is one of the factors that will be used to evaluate the effect of usage satisfaction in using cloud computing services. 


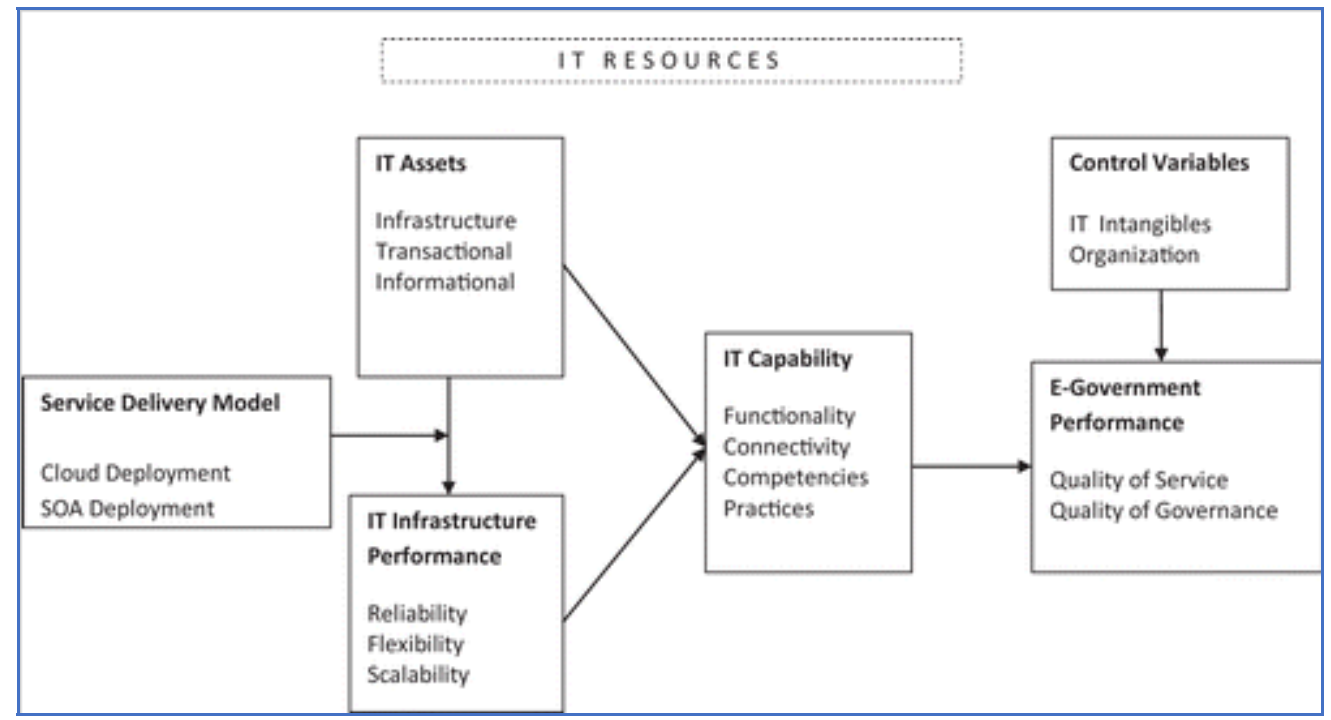

Figure 7. Priori Conceptual framework used (Deepak et al., 2016).

Table 2 shows the gaps from the previous studies. In this table, most of the previous study focused on services. Services are important in implementing cloud application in managing the data. It is important for computer technology to analyse data using cloud technology. However, it is important to evaluate the performance as discussed in Aggeliki et al. (2014) and Gangwar et al. (2015). Performance goes hand in hand with cloud computing services. In contrast to the previous study, our research is to identify the gaps to analysis heterogeneous data from internal sources and external sources.

Table 2. Review on current framework

\begin{tabular}{lllll}
\hline \multirow{2}{*}{ Authors } & IT & Computer & End User & \\
& Infrastructure & Services & Usage
\end{tabular}$\quad$ Application Performance Quality

Aggeliki et al., (2014)

Mohammed et al., (2016)

Gangwar et al., (2015)

Kaisler et al., (2012)

Deepak et al. (2016)

Marten et al. (2015)

\section{Conclusion}

This paper reviewed the factors of cloud computing usage satisfaction. In this paper, it has shown that the factors focused to evaluate cloud computing usage satisfaction are security, 
efficiency and performance, cost, organisation and technology. Many studies on cloud computing usage satisfaction has been conducted. There are few study accepted the advantages and disadvantages of cloud computing. It has found that with the usage of cloud computing it able to reduce the cost of operating in IT management (Amron, Ibrahim \& Chuprat, 2017). Although it has mentioned in many studies that there are concerns on security of cloud computing, security on cloud computing platforms has gone through many technology advancement focuses on the issues of privacy of user's data safety. Thus it is important for IT to identify the threats and risk pertaining to the usage of cloud computing. In addition, with the right amount of knowledge and exposure of this technology it able for use to work efficiency. User that are failing in using cloud computing are usually have lower intentions to use this technology (Aharony, 2014). Various study mentioned that good performance of cloud computing can benefit the user. As for organisational, previous studies highlighted top management play an important role in decision making process. Organisation must able to provide training theoretical and practically since it is part of user's technology readiness. The features that are available in this technology probably not been seen clearly enough by users (Inmora \& Suwannahon, 2017). Recommendation in Aharony (2014), organisation need to exhibit the ease of use of cloud computing. Using cloud computing can impact on everyday life which it brings a lot of benefits as well as challenges. Thus it hopes that this study will added some value on how society should think forward about the cloud computing in the future.

\section{References}

Adeniran, P. (2011). User satisfaction with academic libraries services: Academic staff and students perspectives. International Journal of Library and Information Science, 3(10), 209-216. https://doi.org/10.5897/IJLIS11.045

Adjei, J. K. (2015). Explaining the role of trust in cloud computing services. Info, 17(1), 54-67. https://doi.org/10.1108/info-09-2014-0042

Aharony, N. (2014). Cloud computing: Information professionals' and educational technology experts' perspectives. Library $\mathrm{Hi}$ Tech, 32(4), 645-666. https://doi.org/10.1108/LHT-02-2014-0024

Amron, M. T., Ibrahim, R., \& Chuprat, S. (2017). A Review on Cloud Computing Acceptance Factors. Procedia Computer Science, 124, 639-646. https://doi.org/10.1016/j.procs.2017.12.200

Christopher, O., Temitayo, F., \& Comfort, D. (2014). The Impact and Challenges of Cloud Computing Adoption on Public Universities in Southwestern Nigeria. International Journal of Advanced Computer Science and Applications, 5(8). https://doi.org/10.14569/IJACSA.2014.050803

Dahiya, D., \& Mathew, S. K. (2016). IT assets, IT infrastructure performance and IT capability: a framework for e-government. Transforming Government: People, Process and Policy, 10(3), 411-433. https://doi.org/10.1108/TG-07-2015-0031 
Dhar, S. (2012). Management Research Review From outsourcing to Cloud computing: evolution of IT services. Management Research Review Strategy \&amp; Leadership Journal of Enterprise Information Management, 35(3), 664-675. Retrieved from https://doi.org/10.1108/01409171211247677//doi.org/10.1108/10878571211242920\%22\%3E https://

Dinev, T., Xu, H., Smith, J. H., \& Hart, P. (2013). Information privacy and correlates: an empirical attempt to bridge and distinguish privacy-related concepts. European Journal of Information Systems, 22(3), 295-316. https://doi.org/10.1057/ejis.2012.23

Gangwar, H., Date, H., \& Ramaswamy, R. (2015). Understanding determinants of cloud computing adoption using an integrated TAM-TOE model. Journal of Enterprise Information Management, 28(1), 107-130. https://doi.org/10.1108/JEIM-08-2013-0065

Kaisler, S., Money, W. H., \& Cohen, S. J. (2012). A decision framework for cloud computing. System Science (HICSS), 2012 45th Hawaii International Conference on, (June 2015), 1553-1562. https://doi.org/10.1109/HICSS.2012.52

Kumar, S. (2013). Cloud Computing for Universities: A Prototype Suggestion and use of Cloud Computing in Academic Institutions. Retrieved from https://pdfs.semanticscholar.org/8fef/1988780ff63429545c88cc0e62ded67c70d6.pdf

Low, C., Chen, Y., \& Wu, M. (2011). Industrial Management \&amp; Data Systems Understanding the determinants of cloud computing adoption. Industrial Management \& Data Systems Journal of Financial Crime The Electronic Library, 111(2), 1006-1023. Retrieved from https://doi.org/10.1108/02635571111161262

Martens, B., Walterbusch, M., \& Teuteberg, F. (n.d.). Costing of Cloud Computing Services: A Total Cost of Ownership Approach. Retrieved from http://citeseerx.ist.psu.edu/viewdoc/download?doi=10.1.1.476.1203\&rep=rep1\&type=pdf

Mohammed, F., Ibrahim, O., \& Ithnin, N. (2016). Factors influencing cloud computing adoption for e-government implementation in developing countries. Journal of Systems and Information Technology, 18(3), 297-327. https://doi.org/10.1108/JSIT-01-2016-0001

Mohammed, F., Ibrahim, O., \& Ithnin, N. (2016). Factors influencing cloud computing adoption for e-government implementation in developing countries. Journal of Systems and Information Technology, 18(3), 297-327. https://doi.org/10.1108/JSIT-01-2016-0001

Mohammed, Z. A., \& Tejay, G. P. (2017). Examining privacy concerns and ecommerce adoption in developing countries: The impact of culture in shaping individuals' perceptions toward technology. Computers and Security, 67, 254-265. https://doi.org/10.1016/j.cose.2017.03.001

Pilevari, N., Eshlaghy, A. T., \& Sanaei, M. (2011). A Framework for Evaluating Cloud Computing User's Satisfaction in Information Technology Management. Int. J. Manag. Bus. Res, 1(4), 231-240. Retrieved from http://ijmbr.srbiau.ac.ir/article_28_1703f062c7e86ba62f5bb7b18b90f272.pdf 


\section{Macrothink}

International Journal of Learning and Development

ISSN 2164-4063 2019, Vol. 9, No. 2

Ramadiani, Azainil, Haryaka, U., Agus, F., \& Kridalaksana, A. H. (2017). User Satisfaction Model for e-Learning Using Smartphone. Procedia Computer Science, 116, 373-380. https://doi.org/10.1016/j.procs.2017.10.070

Tsohou, A., Lee, H., \& Irani, Z. (2014). Innovative public governance through cloud computing: Information privacy, business models and performance measurement challenges. Transforming Government: People, Process and Policy, 8(2), 251-282. https://doi.org/doi:10.1108/TG-09-2013-0033

Wu, D., Hugenholtz, P., Mavromatis, K., Pukall, R., Dalin, E., Ivanova, N. N., ... Eisen, J. a. (2009). CLOUD COMPUTING - An Overview An Overview. White Paper, 462(7276), 1-5. https://doi.org/10.1038/nature08656

Wu, W., Lan, L. W., \& Lee, Y. (2013). Factors hindering acceptance of using cloud services in university: A case study. The Electronic Library, 31(1), 84-98. https://doi.org/10.1108/02640471311299155

Yuvaraj, M. (2015). Problems and prospects of implementing cloud computing in university libraries. Library Review, 64(8/9), 567-582. https://doi.org/10.1108/LR-01-2015-0007

\section{Copyright Disclaimer}

Copyright for this article is retained by the author(s), with first publication rights granted to the journal.

This is an open-access article distributed under the terms and conditions of the Creative Commons Attribution license (http://creativecommons.org/licenses/by/4.0/). 